\title{
Erratum to: The what-where trade-off in multiple-identity tracking
}

\author{
Michael A. Cohen - Yair Pinto • Piers D. L. Howe •
}

Todd S. Horowitz

Published online: 2 August 2011

(C) Psychonomic Society, Inc. 2011

\section{Erratum to: Atten Percept Psychophys}

\section{DOI 10.3758/s13414-011-0089-7}

This article was published with an error in Michael A. Cohen's affiliation address. As shown in this erratum, the country should be USA (not Canada).

The online version of the original article can be found at http://dx.doi. org/10.3758/s13414-011-0089-7.

M. A. Cohen $(\bowtie)$

Department of Psychology, Harvard University,

33 Kirkland St., 760 William James Hall,

Cambridge, MA 02138, USA

e-mail: michaelthecohen@gmail.com

\section{Y. Pinto}

University of Amsterdam,

Amsterdam, Netherlands

\section{P. D. L. Howe}

University of Melbourne,

Melbourne, Australia

T. S. Horowitz

Brigham and Women's Hospital, Harvard Medical School,

Boston, MA, USA 